THURSDAY, SEPTEMBER 22, I870

\section{THE GOVERNMENT AND THE ECLIPSE EXPEDITION}

EVERAL of the correspondents who have been lately so busily engaged in chronicling the scenes of the p:esent terrible war have wound up their descriptions by the remark that they could scarcely get rid of the impression that they have been all the time the sport of horrid dreams-that the carnage has existed only in their imagination, and that civilised Europe has been uninterruptedly pursuing the arts of peace.

Similarly it is difficult for an English man of science, proud of his nation's past achievements in many of the most noble problems, and among them those which have necessitated voyages to various parts of the world-now to vitness a transit of Venus-now to make magnetic observations-now to survey the Polar Regions-and now to observe an eclipse of the sun; to realise the fact that in this present year of grace, 1870 , there exists a British Government which in the curtest possible manner has put a stop to an expedition which promised to add as much to our renown in the present as the expeditions to which we have referred, and many others that we might have mentioned, have done in the past.

The proposed expedition now in question had for its object the observation of the approaching Eclipse of the Sun. A brief statement will suffice to show its importance, and how naturally it followed other similar expeditions.

It is now more than a century and a hall ago since certain things called red flames were seen round the edge of the eclipsed sun; another appearance called the corona, sometimes of great irregularity and magnitude, having been noticed from the highest antiquity. Time went on, however, till only. as lately as ten years ago a British expedition to Spain determined, to the satisfaction of everybody, that these red flames belonged to the sun, and not to the moon, as had been suggested. Here, then, was one great point gained by the help of the British Government-other European Governments, let us add, assisting. This was in 1860 . In 1868 there was another eclipse, this time in India. The Indian side of the Government nobly assisted again by telling off officers, granting money, and affording the use of a ship to a distinguished Frenchman who chose India for his standpoint of observation, the French and German Government expeditions preferring other stations. It is seen, therefore, that the work done at the eclipse of 1868 was Government work, and it was admirable. The nature of the red flames, which had been localised in 1860 , was now roughly determined.

There was still another eclipse in 1869 , visible in Arierica. Here Govermment help was not needed at all, as the eclipse swept right over the land; still it was nobly given, and one of the most important recent contributions to astronomy is the American Government Report, of the observations made by its officers. The American observers fairly broke ground in another branch of the research, the nature-not of the red flames this time but-of the corona; but they did not settle the question, and it now remained for astronomers to "crown the edifice" of all our eclipse work by settling it at the eclipse next December.

Thanks to the Janssen-Lockyer discovery, we can now study the red flames day by day; and, although the corona resists the new method, the discovery, taken in connection with Frankland and Lockyer's observations of the hydrogen spectrum, has yet thrown much light on its possible nature, so that the new method makes observations next December more precious.

Having shown, then, both the importance of the observations of the next eclipse, and the fact that they are the natural sequel of the work which has been done by Government aid, and which, it is not too much to say, could not have been done without it, let us next state some facts with regard to the proposed Expedition. It was first proposed by the council of the Royal Astronomical Society, who appointed a committee of council to take the necessary steps. The Royal Society followed suit, and next a joint committee was formed. To this joint committee were committed the whole of the arrangements. Here, shortly, is the programme agreed upon :-

I. At least two expeditions would be necessary-one to Spain, the other to Sicily.

2. At least 1,000 . would be required for instruments and observatory-building expenses, \&c.

3. The presidents of the Royal and Royal Astronomical Societies and the Astronomer Royal were to form a deputation to the Government to ask for two ships and 5ool, the remainder being subscribed by the societies themselves.

4. The observers were to be carefully organised, and competent persons placed in charge of each branch of the research in each expedition.

It is clear from this that our scientific bodies have done all in their power.

Unofficial pourparlers having led to the belief that the Government would not be found wanting on its part, those interested in the work spared no pains to organise the expedition as minutely as possible, and all the best observers came forward to make it second to none of its predecessors.

Here is the official list of those who were prepared to take part in the observations:-

Spectroscopy.-Mr. Lockyer, Dr. Gladstone, Mr. Buckingham, Lieut. Brown, Mr. T. W. Backhouse, Lieut. Collins, Rev. A. W. Deey, Lieut. Davies, Mr. G. Griffith, Mr. W. B. Gibbs, Rev. H. A. Goodwin, Mr. S. Hunter, Mr. W. A. Harris, Rev. F. Howlett, Mr. W. Ladd, Capt. J. P. Maclear, Rev. S. J. Perry, Mr. A. C. Ranyard, Mr. G. M. Seabroke, Mr. H. Tomlinson, Mr. Pedler.

Polarisation.--Prof. Pritchard, Mr. R. Abbatt, Mr. Bushell, Mr. Chambers, Mr. G. Griffith, Mr. W. B. Gibbs, Rev. F. Howlett, Mr. W. Ladd.

Photography.-Mr. Browning, Mr. Brothers, Lieut. Abney, Mr. Buckingham, Lieut. Brown, Mr. Chambers, Mr. Clodd, Mr. R. Sedgfield.

Genural Objects.-Mr. Lassell, Col. Strange, Mr. Dallmeyer, Mr. J. Bonomi, Mr. E. J. Lowe, Prof. J. Phillips, Prof. H. E. Roscoe, Mr. G. J. Stoney, Mr. C. G. Talmage, Mr. C. B. Vignoles.

Generat Assistance-Mr. R. Abbay, Mr. R. Inwards, Lord Lindsay, Mr. W. J. Lewis, Rev. W. Monk, Mr. R. 
S. Newall, Mr. L. B. Phillips, Mr. W. Pole, Mr. F. C. Penrose, Prof. Tyndall, Mr. R. Webster, Mr. J. E. Backhouse, Mr. E. E. Bowen, Col. Drayson, Admiral Ommanney, Mr. Thos. Slater, Mr. P. E. Sewell, Mr. W. Rossiter, Capt. Noble, Mr. W. K. Clifford, Mr. W. H. H. Hudson.

Here was a rich promise of a victorious campaign, and the scientific world already congratulated itself on being able at last to "settle the corona," when suddenly, as a bolt out of the blue, came a letter from the Admiralty declining even a single ship, on the ground that such a purpose was entirely foreign to the purpose for which Parliament places funds at the disposal of the Naval Department.

We think we had better leave this astounding statement as it stands. It seems really as if the present Admiralty authorities are in absolute ignorance as to the real facts of the case ; as to what England has done before; as to what precedents exist to which men of science can point.

Under these circumstances we trust that an appeal will be made to $\mathrm{Mr}$. Gladstone, whose culture, wider than that of his more prominent colleagues, will at once grasp the huge Philistinism of this proceeding. Should he reverse their decision, which he may fairly do, on the mere ground that it is against all precedent, assuredly the scientific men of Britain will hail it as a happy omen-an indication that the hope experienced by Prof. Huxley at Liverpool the other day will, in time, be realised. If, on the other hand, the decision is to stand, it must be distinctly understood that, both in the judgment of our contemporaries and of posterity, it will, as has been already been pointed out in the daily press, bring shame upon the scientific repute of England, who now, with her forces all ready to achieve another victory over nature, is held back by "My Lords" for the sake of a few pounds sterling. Surely there is little hope for us if in such a campaign as this we are to succumb to a

Lust of gold
And love of a peace that is full of wrongs and shames; Hortible, monstrous! not to be told.

REPLY TO PROFESSOR HUXLEY'S INAUGURAL ADDRESS AT LIVERPOOL ON THE QUESTION OF THE ORTGIN OF LIFE

I.

SPEAKING with all the authority which years of earnest and successful labnur have conferred, and, moreover, "from the elevation upon which the suffrages of his colleagues had for the time placed him," Prof. Huxley has just given us in his Inaugural Address, as President of the British Association for the Advancement of Science, a "history of the rise and progress of a single biological doctrine"--that first proclaimed by Francesco Redi, and to the effect that Every living thing proceeds from a pre-existing living thing.

However reluctant to enter a protest against what has been said by an eminent scientific man, for whom I have always entertained the greatest respect and esteem, I feel so strongly that the representations which have been made concerning a subject to which I have directed the most earnest attention for the last eighteen months, are not only inadequate, but altogether incapable of being regarded as an impartial statement of the main points at issue, that I cannot hesitate as to the propriety of publicly expressing this opinion.

Fearful, therefore, lest harm should be done to the cause of science by this address, through the great influence of the speaker, and mindful of the monentous issues which turn upon the proper solution of the question under discussion, I-sinking all personal feelings, risking all imputations, anxious only that the truth should be known-will venture to state what really seems to me to be the true aspect of the problem, and how far the remarks of Prof. Huxley really bear upon this, or have been, in other respects, not sufficiently explicit.

The doctrine, whose history Prof. Huxley professes to trace, and whose probable truth he thinks remains unshaken, has reference to a question which is of more fundamental importance than any other throughout the whole range of Biological science. It is either true that all living matter, without exception, comes into being in connection with pre-existing living matter, or else it is true that some living matter can arise from non-living materials free from all connection with pre-existing living matter. This alternative is one the full meaning of which may, perhaps, be realised better by putting another, which, though strictly analogous, is somewhat freer from mystery. It may, then, similarly be said, it is either true that all crystalline matter, without exception, comes into being in connection with pre-existing crystalline matter, or else it is true that some crystalline matter can arise from non-crystalline materials, free from all connection with preexisting crystallinematter. Matter when it passes into the crystalline cordition exhibits properties of a certain kind, and when it passes into the living condition it exhibits properties of another kind, to which we commonly apply the term "vital." Now the question in each case is, whether by mere concurrence of certain physical conditions, aiding and abetting the inherent properties of the matter itself, some kinds of matter can fall into modes of combination called crystalline, whilst other kinds are capable of falling into modes of combination called living; or whether, in each case, a pre-existing "germ" of the particular kind of matter is necessary, in order to determine, in suitable media, either of these modes of combination. Are we to believe that crystals can appear in no solution whatsoever without the pre-existence in that sulution of certain crystalline germs, ${ }^{*}$ and similarly that living things can arise in no solution whatsoever with out the pre-existence in such solution of living germs? To many persons it may at first sight seem that there is no analogy between the two cases; such, however, is not the opinion of very many who are best entitled to speak on the subject. II It is admitted by them that the analogy is of the closest description; and it is interesting to note that although the actual evidence which can be brought to bear upon these two questions is very similar in kind, and alike conflicting in nature, the generally received opinions as regards the proper answers to be given to these two questions have inclined to the view that, whilst it is possible for crystals to originate de novo, it is at present impossible for living things to originate after this fashion. * It must not be supposed that this is a mere hypothetical case,
On the subject of crystallisation generally in supersaturated solitions, I will quote the following passage from. Watts" Dictionary of Chemistry, Vol. v., p. 349. - " This sudden crystallisation, if not produced by cold, appears to depend essentially on contact of the solution with small solid, perhaps crystalline particles; for it is not produced by passing air previously purified by oil of vitriol through the solution, or by agitation with a glass rod pre-
vionsly purified from dust by ignition. According to Violette and DeGernez, viously purified from dust by ignition. According to Violette and De Gernez, the sudden crystallisation is in all cases induced only by contact zuith a crystal of the same snlt, possessing the same form and degree of hydration as the crystals, which separate out: and in the case of those supersaturated solutions which crystallise suddenly on exposure to the air, it is due to the presence of minute particles of that salt floating in the air. From an experiment of De Gernez it appears that microscopic crystals of sodic sulphate may be obtained by passing alr, even in the open country, through pure water, and evaporating the water on a glass plate. Jeannel, however, denies the necessity of contact with the salt actually contained in the solution. He finds, indeed, that a supersaturated solution of sodic acetate may be made to crystallise by contact with any solid substance (a piece of paper for example), and a solution of sodic tartrate by contact with a clean, dry, glass rod " Here, then, we have also a veritable "germ" controversy. I was informed, however, a few weeks ago by Prof. Frankland that even in the case of sodic sulphate it had lately been shown that, inder certain conditions, crystallisation can certainly take place where no crystalline germ could possibly have existed. The "germ" theory of the origin of crystals in supersaturated solution, has, therefore, been overthrown. This has been possible, however, only because it has been more easy to show that a given set of conditions are inimical to the existence of a crystal, than it has yet been to induce people to believe that any given set of conditions are incompatible with the existence of living matter.

$\mathrm{I}_{\mathrm{t}}$ is worthy of remark, however, that the germ controversy concerning crystals can only be settled in the minds of those who are content to accept the high probability that the properties of any inzisible portions of crystalline matter would correspond with the properties which similar visible crystalline matter is known to display. It is this reluctance to admit an equally high probability in the case of living matter, which alone causes the sister controversy to continue. Otherwise the question would have been settled long ago. $t$ The analogy between the supposed possible origins of crystals and organisms in solutions has been rendered much more obvious since the discovery by the late Professor Graham, that when dissolved the saline substance does not remain as such in solution, but that the acid and the base exist separately, and are separable by a process of dialysis. When crystallisation takes place, therefore, we have a combination of materials taking place similar to, though simpler than, what may be presumed to take place in the genesis of a living thing. 